\title{
Analysis of a Blumeria graminis-Secreted Lipase Reveals the Importance of Host Epicuticular Wax Components for Fungal Adhesion and Development
}

\author{
Jie Feng, ${ }^{1}$ Feng Wang, ${ }^{1}$ Guosheng Liu, ${ }^{1}$ David Greenshields, ${ }^{1}$ Wenyun Shen, ${ }^{2}$ Susan Kaminskyj, ${ }^{1}$ \\ Geoff R. Hughes, ${ }^{3}$ Youliang Peng, ${ }^{4}$ Gopalan Selvaraj, ${ }^{2}$ Jitao Zou, ${ }^{2}$ and Yangdou Wei ${ }^{1}$ \\ ${ }^{1}$ Department of Biology, University of Saskatchewan, 112 Science Place, Saskatoon, SK S7N 5E2, Canada; ${ }^{2}$ National \\ Research Council of Canada, Plant Biotechnology Institute, Saskatoon, SK S7N 0W9, Canada; ${ }^{3}$ Department of Plant \\ Sciences, University of Saskatchewan, 51 Campus Drive, Saskatoon, SK S7N 5A8, Canada; ${ }^{4}$ State Key Laboratory of \\ Agrobiotechnology, Department of Plant Pathology, China Agricultural University, Yuanmingyuan West Road 2, Beijing \\ 100094, P. R. China
}

Submitted 28 March 2009. Accepted 1 July 2009.

\begin{abstract}
The biotrophic powdery mildew fungus Blumeria graminis releases extracellular materials to the surface of fungal infection structures that facilitate anchoring them to hydrophobic plant surfaces prior to infection; however, the chemistry of fungal adhesives and the mechanism of adhesion remain largely unclear. Expressed sequence tag analysis led to identification of a secreted lipase, Lip1, from $B$. graminis. Expression of LIP1 is dramatically upregulated during the early stages of fungal development. Lip1, secreted to the surface of fungal cell walls, possesses lipolytic activity against a broad range of glycerides and releases alkanes and primary fatty alcohols from the epicuticular wax of wheat leaves. Of the epicuticular wax components released by Lip1 activity, long-chain alkanes are the most efficient cues for triggering appressorium formation. Pretreatment of wheat leaves with Lip1, thereby removing leaf surface wax, severely compromises components of fungal pathogenicity, including conidial adhesion, appressorium formation, and secondary hypha growth. Our data suggest that Lip1 activity releases cues from the host surface to promote pathogen development and infection.
\end{abstract}

Hydrophobic epicuticular waxes minimize the adhesion of water and other particles on the surface of leaves, thereby keeping leaves clean and enhancing their ability to trap light for photosynthesis (Samuels et al. 2008). Adhesion to host surfaces represents an initial strategy for successful infection by many phytopathogenic fungi (Jones 1994; Carver and Gurr 2006). Furthermore, components of the plant surface or cuticle and their breakdown products can be taken up by the pathogen as part of a signaling system triggering spore germination and infection structure differentiation (Pascholati et al. 1992; Francis et al. 1996; Gilbert et al. 1996; Hegde and Kolattukudy 1997;

J. Feng and F. Wang contributed equally to this research.

Corresponding author: Y. Wei; Telephone: +1-306-9664447; Fax: +1-3069664461; E-mail: yangdou.wei@usask.ca

Sequence data is available in EMBL and GenBank databases under accession number EU583448.

* The $\boldsymbol{e}$-Xtra logo stands for "electronic extra" and indicates that a supplemental table is published online and also that Figures 2, 3, 4, and 7 appear in color online.
Skamnioti and Gurr 2007). It is generally accepted that the pathogen firmly attaches to the host surface by release of extracellular materials (ECM) from fungal spores and germlings. ECM-mediated adhesion occurs in a wide range of pathogenic fungi, including the rice blast Magnaporthe grisea (Bourett and Howard 1990); the anthracnose Colletotrichum spp. (Mercure et al. 1994, 1995; Sugui et al. 1998); the rusts Puccinia and Uromyces spp. (Chaubal et al. 1991; Clement et al. 1993, 1994, 1997); and the powdery mildews Uncinuliella australiana (Mims et al. 1995), Erysiphe pisi (Carver et al. 1996; Carver and Gurr 2006), and Blumeria graminis (Carver et al. 1996, 1999; Wright et al. 2002a; Zhang et al. 2005).

Powdery mildew fungi are a group of obligate biotrophic pathogens that cause destructive foliar diseases of many plant species. The cereal powdery mildew B. graminis only infects epidermal cells and colonizes the host surface. B. graminis infection processes and the early interaction with its cereal hosts have been well-documented (Green et al. 2002; Zhang et al. 2005). Adhesives of the powdery mildew fungi B. graminis and $U$. viciae-fabae contain nonspecific esterases and cutinases (Nicholson et al. 1988; Deising et al. 1992; Pascholati et al. 1992), and the isolated B. graminis ECM is able to degrade host surface features (Kunoh et al. 1988), suggesting that lipolytic enzymes such as esterases and cutinases are released into the fungal ECM and lead to adhesion (Walton 1994).

Esterase (EC 3.1.1.1), cutinase (EC 3.1.1.74), and lipase (EC 3.1.1.3) belong to the $\alpha / \beta$-hydrolase family, with a signature catalytic triad Ser-Glu-His (Schrag et al. 1991). Distinction between these enzymes has been proposed based on their substrate specificity and their capacity to hydrolyze esters in solution or emulsion (Chahinian et al. 2002; Schrag et al. 1991). Esterases act on solutions of short-chain fatty acyl esters, whereas lipases have the capacity to act on water-insoluble long-chain fatty acyl groups. Cutinases, considered a link between esterases and lipases for substrate preference (Chahinian et al. 2002), are generally small enzymes of approximately 22 to $25 \mathrm{kDa}$ (Kolattukudy 1984; Longhi and Cambillau 1999) that are active in both soluble-phase and emulsified interface and do not show so-called interfacial activation, a phenomenon commonly observed in lipases (Verger 1997). Although cutinases are also able to efficiently hydrolyze triglycerides (Martinez et al. 1994), they exhibit a higher specificity for short-chain acyl groups, and this feature has been used as an indicator of cutinase activity (Kolattukudy 
1985). In contrast, lipases are larger lipolytic enzymes and can hydrolyze substrates with long-chain fatty acids. The N-terminal sequence of lipases contains a significant hydrophobic region corresponding to the open lid that is responsible for interfacial activation and for determining the substrate specificity (Chahinian et al. 2002).

The roles for cutinases in early stages of fungal pathogenesis have been investigated intensively in some pathogenic fungi for decades, yet many of the conclusions remain controversial. Recently, gene disruption studies on the cutinase gene $\mathrm{Pbcl}$ in Pyrenopeziza brassicae and CUT2 in M. grisea provided genetic evidence that cutinase is a crucial pathogenicity or virulence determinant involved in host penetration ( $\mathrm{Li}$ et al. 2003; Skamnioti and Gurr 2007). However, disruption of CUT2 has no effect on pathogen adhesion to the host surface (Skamnioti and Gurr 2007). Secreted lipases also play a key role in the infection processes of some necrotrophic fungi such as Botrytis cinerea (Comménil et al. 1998, 1999; Reis et al. 2005), Alternaria brassicicola (Berto et al. 1997, 1999), and Fusarium graminearum (Nasser-Eddine et al. 2001; Voigt et al. 2005). When lipase-specific antibodies were added to conidial suspensions of $B$. cinerea (Comménil et al. 1998) and $A$. brassicicola (Berto et al. 1999) prior to inoculation, disease development was largely suppressed, suggesting that the fungal surface-bound lipase is involved in interacting with epicuticular leaf waxes for adhesion or penetration of the fungal propagules. However, when the corresponding gene (lipl) for the $B$. cinerea lipase was disrupted, the knock-out mutants showed no reduction of virulence (Reis et al. 2005). We previously identified a similar lipl gene in $F$. graminearum that was responsible for lipid utilization but dispensable for fungal pathogenicity (Feng et al. 2005). Further analyses of available genomic data revealed that many members of a large lipase gene family are present in necrotrophic fungal pathogens, whereas very few members of the gene family are present in biotrophic pathogens (Supplementary Table S1). This promoted us to investigate the role of lipases in the pathogenesis of biotrophic fungi. In this study, we characterize a secreted lipase from the obligate biotroph Blumeria graminis f. sp. tritici and demonstrate that Lip1-mediated epicuticular wax liquefaction is required for fungal adhesion and development during early stages of infection.

\section{RESULTS}

Lip1 is structurally a typical triglyceride lipase.

To probe the landscape of gene expression during the infection process of $B$. graminis f. sp. tritici on wheat, a cDNA library was constructed from mitochondrial RNA of epidermis of T. monococcum leaves 20 to $48 \mathrm{~h}$ after inoculation (hai) with B. graminis f. sp. tritici (Liu et al. 2005). Expressed sequence tag analysis identified a cDNA similar to extracellular lipase genes in other fungal species. Multiple alignments between the deduced amino acid sequence of this cDNA and lipases from Candida rugosa (Lotti et al. 1993), F. graminearum (Feng et al. 2005), and Geotrichum candidum (Shimada et al. 1990) suggested that the predicted protein of this cDNA is a triglyceride lipase belonging to the C. rugosa lipase family (data not shown). This gene was named LIP1.

Polymerase chain reaction (PCR) amplification of $B$. graminis f. sp. tritici genomic DNA with $L I P 1$-specific primers produced a fragment with sequences identical to the cDNA, indicating no introns in the LIP1 gene. Southern blot analysis using the fulllength $L I P 1$ cDNA to probe the digested $B$. graminis f. sp. tritici genomic DNA indicates that $L I P l$ is present as a single copy in the genome of B. graminis f. sp. tritici (Fig. 1A).

The deduced amino acid sequence of LIPl contains a predicted N-terminal signal peptide, suggesting that Lip1 is a secreted protein. The predicted mature Lip1 protein has an estimated molecular mass of $60.8 \mathrm{kDa}$. Using Lip1, CrLip2 from C. rugosa (Lotti et al. 1993), and Lip1 from F. graminearum (Feng et al. 2005) to query the Broad Institute Whole Genome Database identified putative Lip1 orthologues from other fungal species. Any Blast hit that has a molecular mass at 50 to $80 \mathrm{kDa}$ and contains the two fungal lipase signatures was considered to be a member of the C. rugosa lipase-like lipase family. Of the fungal genomes investigated, 12 to 23 Lip1-like sequences were found in most of the pathogenic and the saprophytic filamentous fungi but only a few in the biotrophic fungi, including Ustilago maydis and Puccinia graminis. This reduction in Lip1-like sequences is consistent with a biotrophic lifestyle, in which damage to the host and releasing of cell wall fragments by hydrolysis enzymes should be minimized (Mendgen and Hahn 2002).

\section{Expression of LIP1 gene is differentially induced during infection process.}

Northern analyses were performed to investigate the expression profile of $B$. graminis $\mathrm{f}$. sp. tritici transcripts during the infection process. Transcripts of $B$. graminis f. sp. tritici $C A P 20$ started to accumulate at 3 hai, peaked at 6 to 12 hai (correlating with appressorium formation), and decreased after 12 hai (Fig. 1B), whose expression profile essentially agrees with that described in $B$. graminis f. sp. hordei (Both et al. 2005). High levels of transcripts at 96 to 144 hai were associated with conidiation (Fig. 1B). We also tracked the expression pattern of the $T E F 1$, a constitutive expression control, to monitor fungal biomass during the development of fungi (Dean et
A

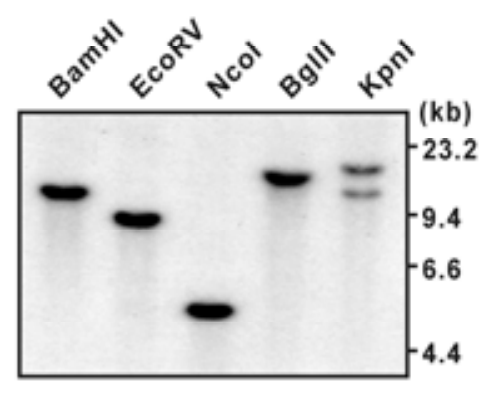

B The infection time course (hai)

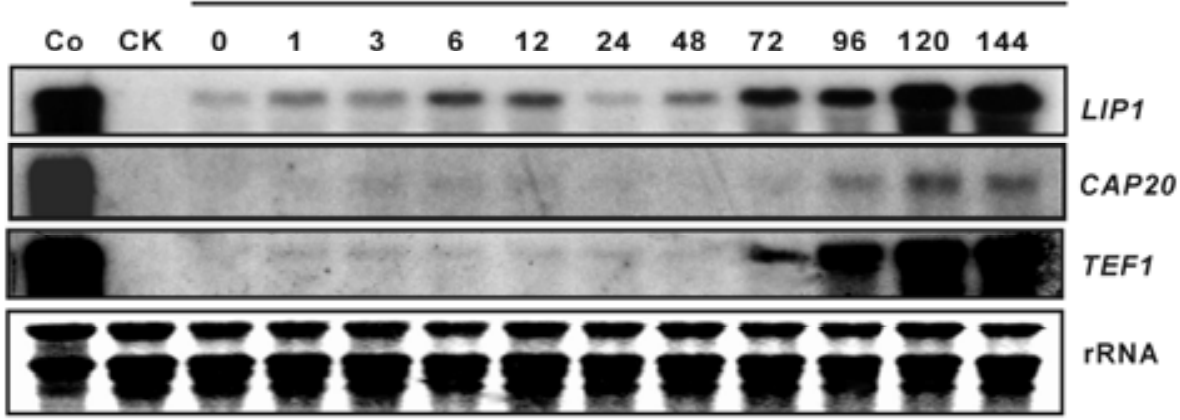

Fig. 1. Southern and Northern analyses of LIP1. A, Genomic DNA of Blumeria graminis f. sp. tritici was digested with the indicated restriction enzymes and the Southern blot was hybridized with ${ }^{32} \mathrm{P}$-labeled LIP1 cDNA. The LIP1 sequence contains one recognition site for KpnI and none for other restriction enzymes. B, Total RNA was extracted from conidia of B. graminis f. sp. tritici (Co), noninoculated wheat leaves (CK), and inoculated leaves harvested at 0 to $144 \mathrm{~h}$ after inoculation. The blot was probed successively with LIP1, CAP20, and TEF1 cDNAs. 
al. 2002). TEF1 transcripts were detected at low but steady levels among samples from 0 to 48 hai, consistent with minimal biomass changes within this period. The LIPl transcript was consistently expressed at higher levels at all time points compared with marker genes that represented biomass and showed a conspicuous expression peak at 6 to 12 hai, a phase corresponding to the formation of the appressorial germ tube. B. graminis f. sp. tritici biomass accumulated between 72 and 144 hai, as indicated by the increase of TEF1 transcripts. Accordingly, the LIPl transcripts increased during this period. However, enhanced expression of LIP1 started at 48 to 72 hai and remained high until 96 hai, correlating with secondary elongation hypha development. There was also a dramatic increase in LIPI expression at 96 to 120 hai in association with conidiation, which was more striking than the progressive change observed in the $T E F 1$ transcript at the same time point. These results suggest that the expression level of LIPl was upregulated at several stages tightly associated with fungal primary and appressorial germ tube formation, and secondary hypha development and conidiation.

\section{Lip1 shows a broad substrate activity.}

High-level expression of LIPl during B. graminis f. sp. tritici development led us to investigate its possible function during fungal pathogenesis. Recombinant Lip1 protein was produced in Escherichia coli M15 cells harboring plasmid pQE60-Lip1 (Fig. 2A). However, no lipolytic activity was detected from the purified protein. We then expressed Lip1 in Pichia pastoris X-33 cells using the EasySelect Pichia expression vector pPICZ $\alpha \mathrm{A}$. Western analysis revealed a single band at approximately $60 \mathrm{kDa}$, which confirmed not only the presence of Lip1 in or on the $P$. pastoris transformant but also the specificity of the primary antibody we prepared (Fig. 2B).

To examine lipolytic activity of Lip1, we performed both tributyrin emulsion and rhodamine-B fluorescence assays. Hydrolysis of tributyrin produces a clear zone around the colony on tributyrin emulsion plates whereas, in rhodamine B assay, free fatty acids produced by hydrolysis of lipid substrates form
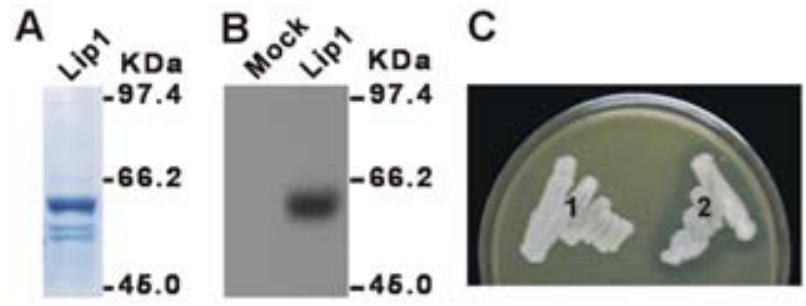
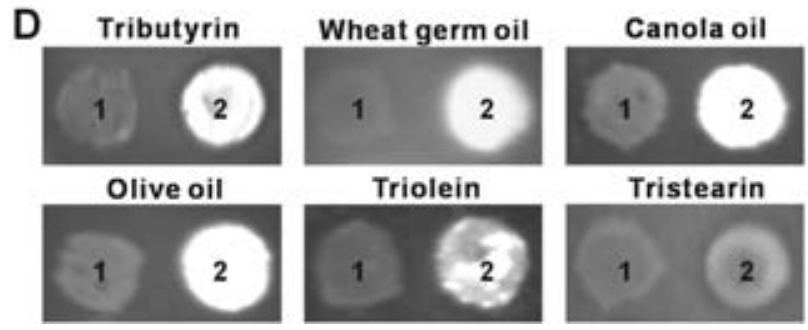

Fig. 2. Production and lipolytic activity of recombinant Lip1. A, Protein purified from Escherichia coli M15 cells harboring pQE60-Lip1 was separated on acrylamide gel and visualized with Coomassie blue staining. B, Western blot analysis of proteins extracted from Pichia pastoris cells harboring pPICZ $\alpha$ A (Mock) or pPICZ $\alpha$ A-Lip1 (Lip1). C and D, Analysis of lipolytic activity of Lip1 expressed in $P$. pastoris. The $P$. pastoris cells harboring pPICZ $\alpha \mathrm{A}$ (1) or pPICZ $\alpha$ A-Lip1 (2) were grown on BMMY (1\% yeast extract, $2 \%$ peptone, $100 \mathrm{mM} \mathrm{KH}_{2} \mathrm{PO}_{4}[\mathrm{pH} \mathrm{6.0])} \mathrm{plates} \mathrm{containing} \mathbf{C}$, $1 \%(\mathrm{wt} / \mathrm{vol})$ tributyrin or $\mathbf{D}, 0.0001 \%(\mathrm{wt} / \mathrm{vol})$ rhodamine-B and $1 \%$ (wt/vol) lipid substrates as indicated.

a fluorescent complex with rhodamine B (Feng et al. 2005). In the tributyrin plate assay, a clear zone was observed only at the colony peripheral of the $P$. pastoris transformant containing pPICZ $\alpha$ A-Lip1, whereas the empty vector-transformed $P$. pastoris strain did not produce any secretory lipolytic activity under the condition (Fig. 2C). The most appropriate way to categorize an enzyme as a lipase is to test whether it can hydrolyze long-chain acyl glycerols (Schmid and Verger 1998). This was confirmed by the rhodamine-B assay, in which fluorescence was detected from the pPICZ $\alpha$ A-Lip1 transformant on plates containing tributyrin (glyceryl tributyrate, $\mathrm{C} 4$ ), triolein (glyceryl trioleate, C18), tristearin (glyceryl tristearate, C18), wheat germ oil, canola oil, or olive oil as lipid substrate (Fig. 2D). These results provide direct evidence that Lip1 is a triglyceride lipase and that it possesses lipolytic activity on a broad range of lipid substrates regardless the length and the saturation of the fatty acid moieties.

\section{Secreted Lip1 protein predominately localizes to the surface of fungal infection structures.}

To reveal the localization of Lip1 during B. graminis f. sp. tritici infection and development, an immunolocalization assay was conducted with anti-Lip1 IgG as the primary antibody and FluoroLink Cy 3 as the secondary antibody. Under a confocal laser-scanning microscope, a strong immunofluorescence signal was observed on the surface of $B$. graminis $\mathrm{f}$. sp. tritici conidia (Fig. 3A). Labeling of individual conidia was stronger on both poles than on the side face, with a dome-shaped pattern of

A

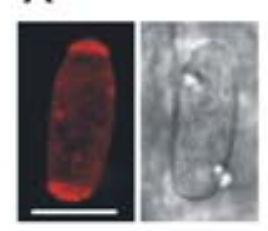

B

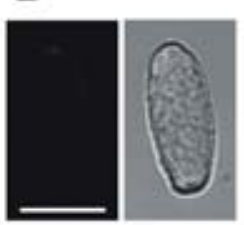

D
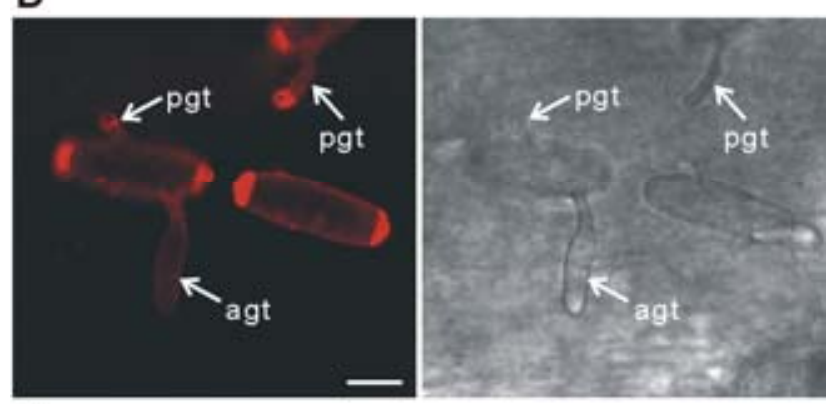

E

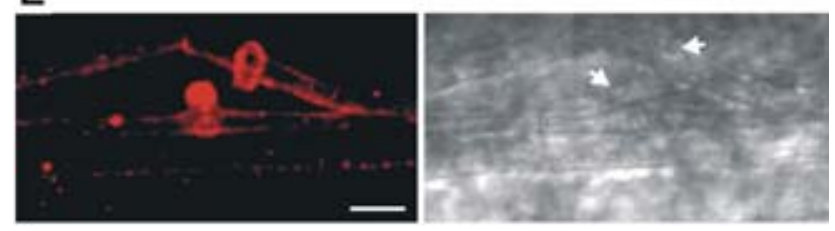

Fig. 3. Lip1 localization during development of Blumeria graminis f. sp. tritici on wheat leaf surface. Conidia or infected leaf samples were incubated sequentially with $\mathbf{A}, \mathbf{C}$, and $\mathbf{D}$, the primary antibody from Lip1-immunized rabbit or $\mathbf{B}$, preimmune serum and FluoroLink CyTM3-labeled goat anti-rabbit immunoglobulin G. Images were obtained by confocal laser-scanning microscopy. Bar $=10 \mu \mathrm{m}$. Mature conidia $\mathbf{A}$, with or $\mathbf{B}$, without Lip1-antiserum preincubation. C, Mature conidium after plasmolysis. The arrowhead indicates the plasma membrane separated away from cell wall. D, Primary (pgt) and appressorial germ tubes (agt) on the leaf surface at $6 \mathrm{~h}$ after inoculation (hai). E, Secondary hyphae on the leaf surface at 168 hai. Arrowheads indicate secondary penetration sites. 
rings. A similar distribution pattern of extracellular mucilage has been observed on fresh conidia of the powdery mildew fungus Uncinuliella australiana (Mims et al. 1995). In the control treatment, when preimmune rabbit serum was used instead of the primary antibody, no labeling signal could be detected (Fig. 3B). Plasmolysis of conidia in $0.8 \mathrm{M} \mathrm{NaNO}_{3}$ for $30 \mathrm{~min}$ before fixation revealed that Lip1 is localized to the cell wall rather than the plasma membrane (Fig. 3C). On germinated conidia from the surface of wheat leaves, fluorescence was abundant at the tip of the primary germ tube and slightly weaker on the appressorial germ tube (Fig. 3D). Fluorescence was also detected on secondary hyphae growing on the leaf surface, with the secondary infection sites showing the most prominent accumulation (Fig. 3E). Taken together, the immunolocalization data suggest that regional and temporal Lip1 regulation plays a role in $B$. graminis $\mathrm{f}$. sp. tritici infectionrelated development on its wheat host.

Lip1 mediates liquefaction of wheat leaf epicuticular wax.

To investigate the effect of Lip1 activity on leaf epicuticular wax, we dipped wheat leaves into 48-h culture supernatants of $P$. pastoris transformants containing either pPICZ $\alpha$ A-Lip1 (Lip1) or pPICZ $\alpha \mathrm{A}$ (mock treatment) for 20 or $30 \mathrm{~min}$. Water droplets $(5 \mu \mathrm{l})$ containing trace amounts of aniline blue readily
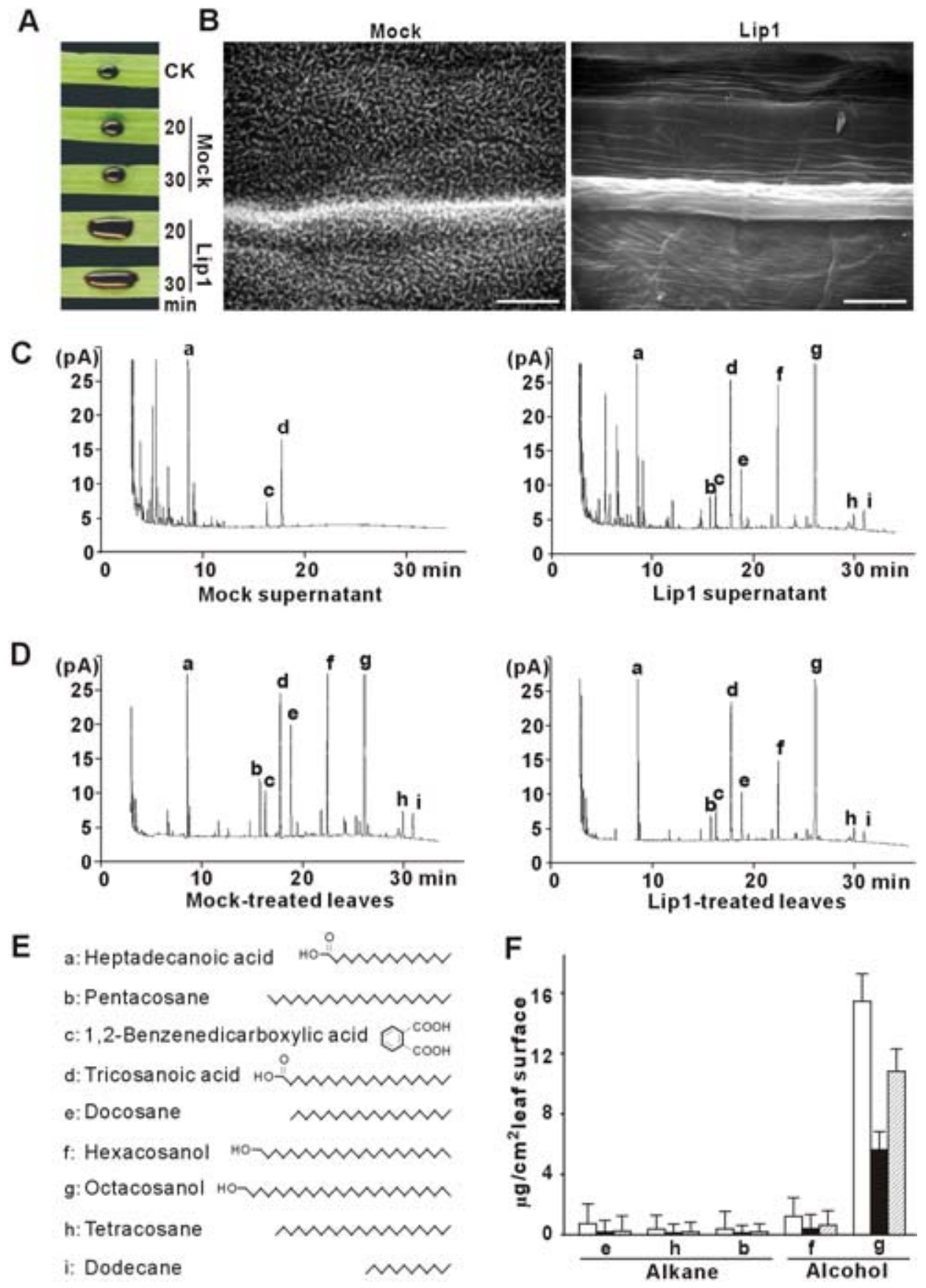

Fig 4. Effect of Lip1 treatment on wheat leaf surface wax. A, Hydrophobicity assays for the leaves pretreated with 48-h culture supernatant of Pichia pastoris transformants containing pPICZ $\alpha$ A (Mock) or pPICZ $\alpha$ A-Lip1 (Lip1) for 20 or $30 \mathrm{~min}$. B, Scanning electron microscopy for the leaves pretreated with mock or Lip1 for $30 \mathrm{~min}$. Bar $=100 \mu \mathrm{m}$. C and $\mathbf{D}$, Gas chromatography (GC) analysis of wheat surface wax components liquefied by Lip1. E, Selected peaks from GC identified by mass spectrometry analysis. F, Alkanes and primary fatty alcohols in the wax extract from mock-treated leaves (blank), Lip1treated leaves (black), and Lip1 supernatant (hatched) were calculated into micrograms of component per leaf area to illustrate the quantitative potential of Lip1 on wax liquefaction. 
spread out on the leaf surface treated with Lip1 compared with the mock-treated leaves, suggesting a reduction in leaf surface hydrophobicity (Fig. 4A). To further investigate the structural changes on the leaf surface, leaves of both treatments were freeze dried and examined with scanning electron microscopy (SEM). Protruding epicuticular wax crystalloids were evident on the surface of the mock-treated leaf but completely absent from the leaf treated with Lip1 (Fig. 4B), indicating that Lip1 possesses the ability to liquefy leaf epicuticular wax.

To determine which wax components were liquefied by Lip1 treatment, we analyzed total lipids liquefied into the supernatants as well as what remained on the surface from the leaves after Lip1 or mock treatment. The lipid extracts were separated through gas chromatography (GC) and subjected to mass spectrometry (MS) analyses. Alkanes, including docosane (C22), tetracosane $(\mathrm{C} 24)$, and pentacosane $(\mathrm{C} 25)$, and primary fatty alcohols, including hexacosanol (C26) and octacosanol (C28), were identified from the Lip1 supernatant but absent in the mock supernatant (Fig. 4C and E). These molecules were derived from the leaf surface because similar components were identified from both Lip1- and mock-treated leaves (Fig. 4D). Octacosanol was found to be the most abundant component of epicuticular wax on wheat leaves. Calculation of the amount of wax components per leaf surface area (micrograms per square centimeter) indicated that Lip1 treatment could remove approximately half of the chloroform- or methanol-extractable surface wax from wheat leaves (Fig. 4F).

\section{Wax components are required}

for conidial germination and differentiation.

The major wax components identified from GC-MS, including dodecane, docosane, tetracosane, pentacosane, hexacosanol, and octacosanol, were coated as a thin-layer film on glass slides. B. graminis f. sp. tritici germination, indicated by the presence of primary germ tubes (PGT), and appressorium development were investigated at 24 hai on these coated slides (Fig. 5). On slides without wax coating (CK), less than $30 \%$ conidia could form PGT and very few could develop appressoria or elongation hyphae. Conidial germination was promoted by crude leaf surface wax or wax components, and long-chain alkanes showed the strongest induction, especially with respect
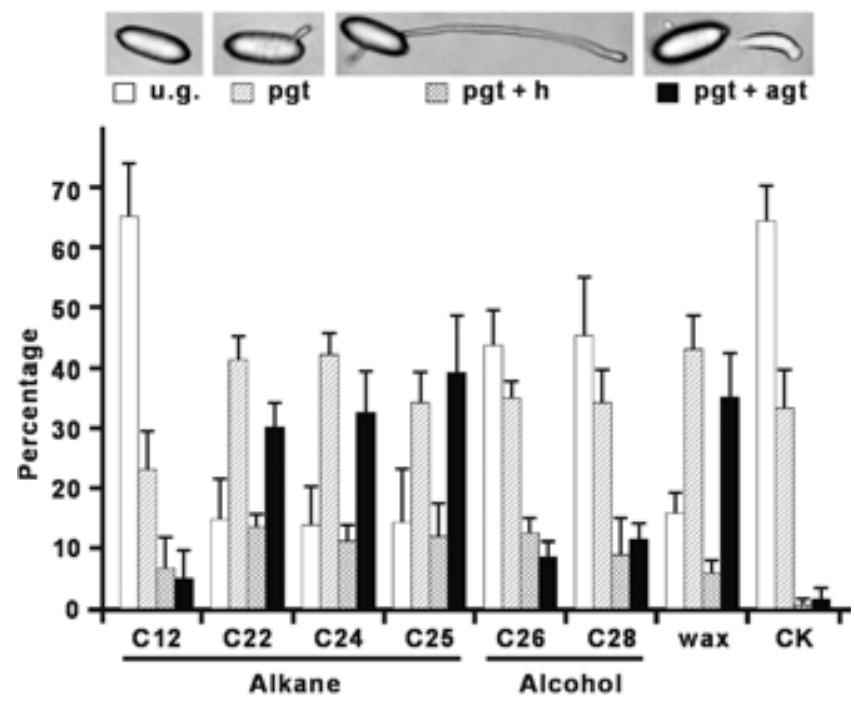

Fig. 5. Effect of wax components on germination of Blumeria graminis $\mathrm{f}$. sp. tritici conidia. Glass slides were coated with the indicated commercial alkanes and alcohols and inoculated with B. graminis $\mathrm{f}$. sp. tritici conidia. Germ tube formation and appressorium development were investigated at $24 \mathrm{~h}$ after inoculation; u.g., ungerminated; pgt, primary germ tube; pgt $+\mathrm{h}$, pgt and hypha; pgt + agt, pgt and appressorial germ tube.
A

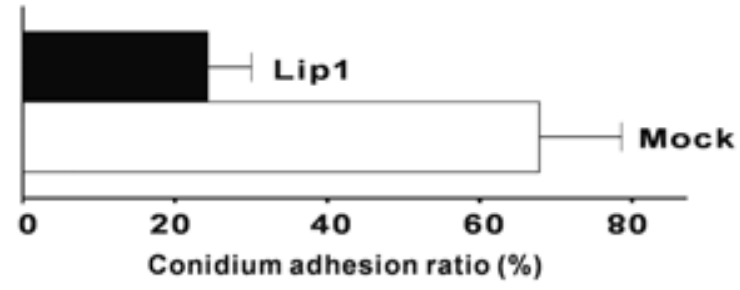

B
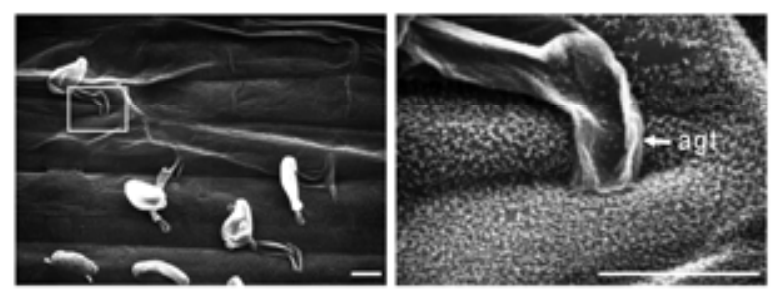

$\mathrm{C}$
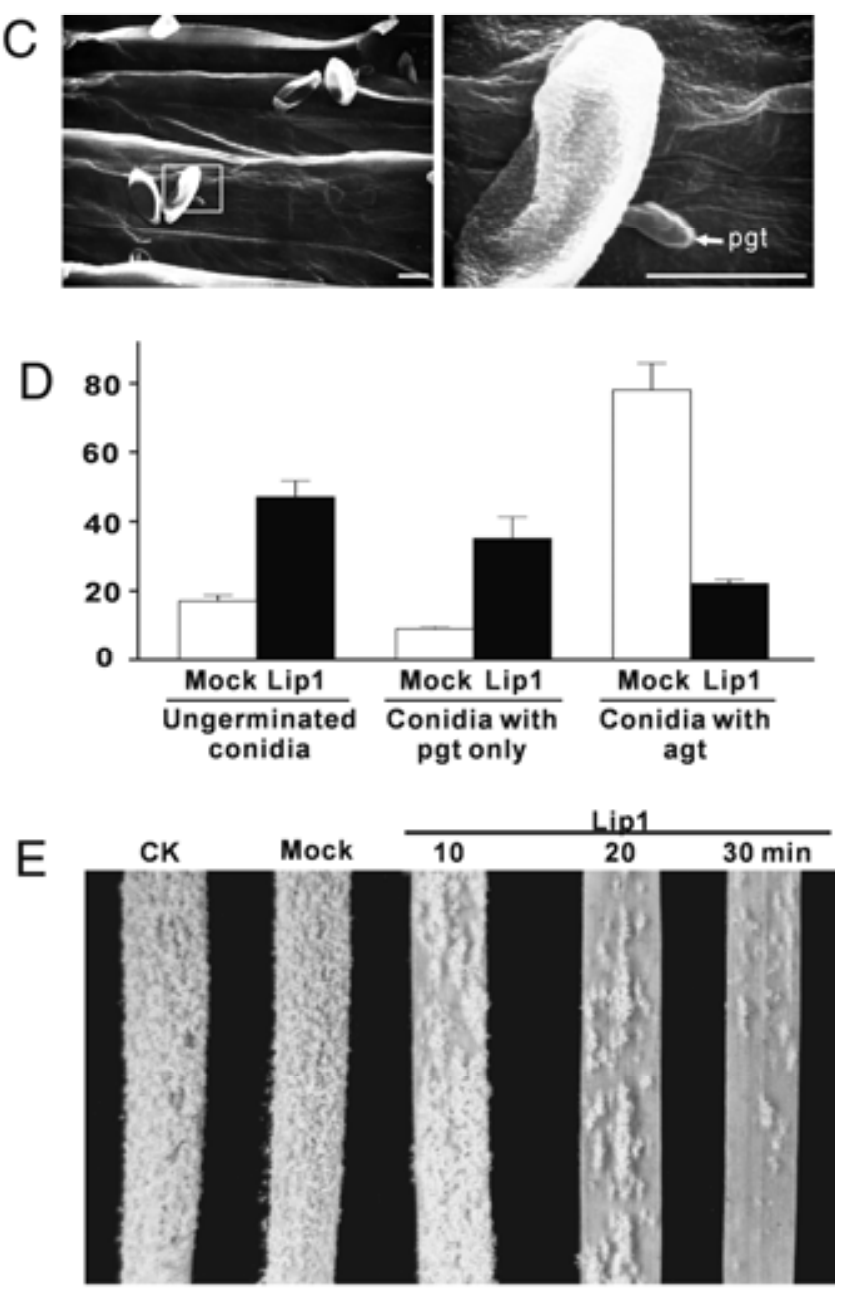

Fig. 6. Effect of Lip1-mediated surface wax liquefaction on early development of Blumeria graminis f. sp. tritici. A, Adhesion of B. graminis f. sp. tritici conidia on wheat leaf surface was inhibited by Lip1 treatment. Numbers of conidia on the same leaf area were counted before and after wash and the ratios were plotted. $\mathbf{B}$ and $\mathbf{C}$, B. graminis f. sp. tritici development on leaf surface at $24 \mathrm{~h}$ after inoculation (hai) after a 12-h pretreatment with culture supernatant of $\mathbf{B}, \mathrm{pPICZ} \alpha \mathrm{A}$ (Mock) or $\mathbf{C}, \mathrm{pPICZ} \alpha \mathrm{A}$ Lip1 transformant. Right panels of scanning electron microscopy images are the magnified areas on left panels. Bar $=10 \mu \mathrm{m}$. D, Analysis of conidial germination and primary germ tube (pgt)/appressorial germ tube (agt) formation at 24 hai. Ungerminated conidia and conidia with only pgt as well as those with agt were plotted as percentages against total conidium numbers. Approximately 100 conidia were counted for each treatment. Mock and Lip1 treatments were performed as the above. E, Symptom development of powdery mildew on untreated (CK), mock-, or Lip1-treated leaves at 10 days postinoculation. 
to the formation of mature appressorium, a structure critical for penetration. Furthermore, we observed a significant progressive increase $(r=0.99, P<0.01)$ in the percentage of mature appressorium-forming conidia $(5.0,30.2,32.7$, and $39.3 \%)$ with the increased length of the alkane carbon chain $(\mathrm{C} 12$, C22, C24, and C25).

\section{Lip1-mediated epicuticular wax liquefaction is involved in fungal adhesion and development.}

To determine the effect of Lip1-mediated epicuticular wax liquefaction on development and pathogenesis of $B$. graminis f. sp. tritici, wheat leaves treated with the 48-h culture supernatant of $P$. pastoris transformants containing either pPICZ $\alpha \mathrm{A}-$ Lip1 (Lip1) or pPICZ $\alpha$ A (mock) for 10 to 30 min were incubated in a growth chamber for $12 \mathrm{~h}$ and then inoculated with B. graminis f. sp. tritici conidia. At 6 hai, conidia could be more readily washed away from Lip1-treated leaves than from mock-treated leaves (Fig. 6A), indicating that Lip1 treatment removes wax components that aid in B. graminis f. sp. tritici adhesion.

We then investigated the effect of Lip1 on B. graminis f. sp. tritici infection-related development by SEM. At 24 hai, on the surface of mock-treated leaves, most conidia produced a primary germ tube and an appressorial germ tube (Fig. 6B). In

A
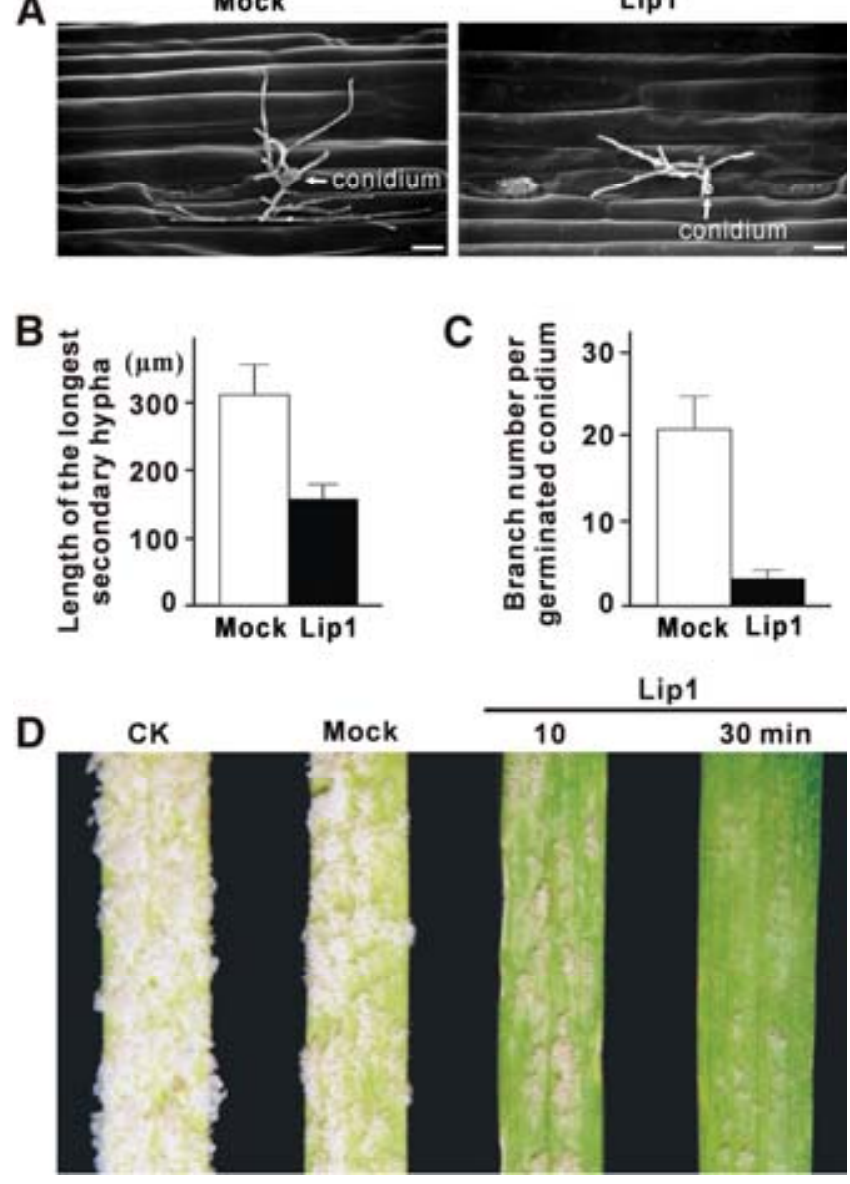

Fig. 7. Effect of Lip1-mediated surface wax liquefaction on secondary hypha development of Blumeria graminis f. sp. tritici. A, Secondary hypha development on leaf surface was examined by scanning electron microscopy at $60 \mathrm{~h}$ after inoculation (hai). Bar $=100 \mu \mathrm{m}$. B, The longest secondary hypha was measured and $\mathbf{C}$, the number of hyphal branches was counted at 60 hai from each of 30 germinating conidia. The average values were plotted to illustrate the significant differences between Mock and Lip1 treatments. D, Symptom development of powdery mildew on untreated $(\mathrm{CK})$, mock-, or Lip1-treated leaves at 10 days after inoculation. contrast, the majority of conidia on Lip1-treated leaves either failed to germinate or produced only the primary germ tube (Fig. 6C and D). After incubation in a growth chamber for 10 days, extensive powdery mildew developed on B. graminis $\mathrm{f}$. sp. tritici-inoculated untreated (CK) and mock-treated leaves, whereas Lip1-treated leaves had few B. graminis f. sp. tritici colonies (Fig. 6E), indicating a reduction of disease severity.

Powdery mildew grows on the surface of hosts by extending secondary elongation hyphae. By 48 hai, primary infection by B. graminis f. sp. tritici establishes functional haustoria associated with appressorial germ tube-mediated penetrations in the leaf epidermal cells, and secondary elongation hyphae begin to develop on the leaf surface. To investigate whether Lip1-mediated leaf epicuticular wax liquefaction was important for secondary hypha development, wheat leaves were inoculated with B. graminis f. sp. tritici conidia and, at 48 hai, treated with the culture supernatant of the $P$. pastoris transformants containing either pPICZ $\alpha$ A-Lip1 (Lip1) or pPICZ $\alpha$ A (mock treatment) for 10 or $30 \mathrm{~min}$. At 60 hai, SEM revealed that Lip1 treatment impaired secondary hypha growth, with reduced secondary hypha elongation and branching (Fig. 7A through C). Late in the infection time course, powdery mildew symptom development on the leaf surface was significantly impaired by the Lip1 treatment (Fig. 7D).

\section{DISCUSSION}

Through characterization of a potent lipase, Lip1, from $B$. graminis f. sp. tritici, we provide several lines of evidence supporting the idea that lipase is critical for fungal adhesion and development on the host surface. First, LIP1 is one of the abundantly expressed Blumeria genes during pathogenesis, and its expression patterns coincide with conidial germination, germ tube development, and conidial formation and maturation. These data are also consistent with the observation that a LIPl orthologue in B. graminis f. sp. hordei was among the 20 most highly expressed genes at the early stages of barley powdery mildew development (Thomas et al. 2002). Second, in situ immunolocalization revealed that Lip1 is secreted to the cell surface and predominantly present on the surface of spore tips, germ tubes, and secondary hyphae, possibly associated with the fungal ECM. Third, the recombinant Lip1 possesses a broad spectrum of substrate specificities on both short- and long-chain fatty acids, which distinguishes it from cutinases that prefer short-chain acyl groups. Finally, Lip1 effectively hydrolyzes leaf epicuticular wax and the hydrolyzed products, especially alkanes, are required for adhesion of conidia and development of germ tubes and secondary hyphae.

Two basic strategies for fungal adhesion to the host surface have been postulated: "passive attachment" resulting from the presence of preformed materials on the fungus surface and "active attachment" requiring the de novo production of fungal adhesives (Carver and Gurr 2006; Jones 1994). Whether the passive or active mechanism is involved in Blumeria spp. adhesion deserves further study but the long-chain fatty acid layers coating Blumeria conidia are expected to lead to immediate passive adhesion through hydrophobic interactions (Senior et al. 1993; Cooper et al. 2000; Carver et al. 2006; Wright et al. $2002 \mathrm{~b}$ ). The adhesion between host plant and powdery mildew could be facilitated via a direct physical interaction between the host and the pathogen in the merit of hydrophobic longchain fatty acids and their derivatives present on the surfaces of both encounters (Fig. 5) (Senior et al. 1993). Furthermore, the secreted Lip1 may enhance the interaction by forming covalent ester bonds among these hydrophobic molecules through its transesterification activities (Gandhi et al. 2000; Schmid and Verger 1998). Immunolocalization analyses to- 
gether with transcript profiling showed that Lip1 is not only present on the surface of mature conidia but also during spore germination, germ tube differentiation, and secondary hypha development. These results suggest that production of Lip1 is constitutive in conidia and inducible upon contact with the plant surface during the infection process, and support the view that both passive and active processes underpin powdery mildew adhesion.

Aerial plant surfaces are covered with a noncellular cuticle, which serves as the initial site of interaction between plants and pathogens. The cuticle is composed of an insoluble polymer of mainly C16 and C18 hydroxy and epoxy fatty acids (cutin) (Kolattukudy 2001) and associated solvent-soluble ubiquitous aliphatic compounds (epicuticular wax, mainly C20-C60 alkanes, alcohols, and ketones) (Samuels et al. 2008). Due to their close association, it is difficult to distinguish between the relative contribution of the cutin matrix and epicuticular wax to the physical properties and the biological functions of the cuticle. This study supports previous observations that octacosanol is the most abundant chemical component of wheat epicuticular wax (Bianchi et al. 1980; Koch et al. 2006). Octacosanol is responsible for induction of infection structures of wheat stem rust $P$. graminis f. sp. tritici (Reisige et al. 2006) and barley powdery mildew B. graminis f. sp. hordei (Zabka et al. 2008). Other long-chain fatty alcohols (>C24) from avocado surface wax components also induce appressorium formation in Colletotrichum gloeosporioides (Podila et al. 1993). However, we found that long-chain alkanes, rather than alcohols, are the most efficient wax component for triggering germination and appressorium development of B. graminis $\mathrm{f}$. sp. tritici. It is possible that alkanes are more hydrophobic than alcohols and, therefore, create a more hydrophobic surface that facilitates fungal development and differentiation. Previous studies showed that germinating conidia and germ tubes were able to gain nutrients and signaling molecules from the host surface (Senior et al. 1993; Carver et al. 1999; Kinane et al. 2000; Nielsen et al. 2000). During infection processes, alkanes released from the epicuticular wax by Lip1 activity may serve as better nutrients or stronger signaling molecules to trigger development and differentiation. The importance of plant epicuticular wax or wax monomers in the induction of fungal infection structures has been addressed from Colletotrichum gloeosporioides (Podila et al. 1993), M. grisea (Hegde and Kolattukudy 1997), B. graminis (Zabka et al. 2008), and Erysiphe pisi (Gniwotta et al. 2005). In the corn smut fungus, Ustilago maydis, a mixture of triacylglycerides from corn oil activates the signaling pathway dependent on both the cAMP pathway and a Ras/mitogenactivated protein kinase pathway to promote and maintain the filamentous growth of the fungus in the host environment (Klose et al. 2004). These results support the view that derivatives of epicuticular wax, perhaps generated by fungal lipolytic activities, could serve as plant-derived signaling molecules.

Lipases in hydrophobic media possess the ability to carry out esterification activity in addition to hydrolysis (Schmid and Verger 1998; Gandhi et al. 2000). It is also possible that Lip1 generates covalent ester bonds between hydrophobic molecules present on the conidium and the host leaf surface through a transesterification reaction. Indeed, hydrophobic layers particularly rich in long-chain fatty acids coat both the conidium and host leaf surface (Senior et al. 1993; Cooper et al. 2000; Samuels et al. 2008). However, the biotrophic nature of $B$. graminis disables gene-disruption strategies to obtain a LIP1-null mutant, thus hindering further investigation into its role in powdery mildew pathogenicity. Nevertheless, our results show that the obligate biotroph $B$. graminis secretes a hydrolytic lipase to facilitate its adhesion and pathogenesis on the host plant.

\section{MATERIALS AND METHODS}

\section{Plant and fungal materials.}

The B. graminis f. sp. tritici strain was maintained and used for inoculation as described (Wei et al. 1998; Liu et al. 2005). Diploid wheat (Triticum monococcum L.) line TM441 inoculated with $B$. graminis $\mathrm{f}$. sp. tritici was used to construct a cDNA library (Liu et al. 2005). All other experiments were conducted on spring wheat (T. aestivum L.) cv. CDC Conway as the susceptible host.

\section{Nucleic acid isolation and Northern and Southern hybridizations.}

Nucleic acid isolation and Northern and Southern hybridizations followed the standard protocols (Sambrook and Russell 2001). Total RNA was extracted from ungerminated conidia and infected leaves at $0,1,3,6,12,24,48,72,96,120$, and 144 hai. In Northern analysis, $20 \mu \mathrm{g}$ of total RNA was fractionated in $1.2 \%$ formaldehyde gels and transferred to Nytran membranes (Whatman, Florham Park, NJ, U.S.A.). The blots were hybridized successively with the ${ }^{32} \mathrm{P}$-labeled cDNAs of LIP1, CAP20, and TEF1. Both CAP20 and TEF1 serve as controls to monitor the $B$. graminis $\mathrm{f}$. sp. tritici transcript profiles during infection. Transcripts of CAP2O homolog in B. graminis $\mathrm{f}$. sp. hordei accumulated during formation of appressoria (Both et al. 2005), whereas TEF1 constitutively expressed in ungerminated and germinated conidia, appressoria, and elongation hyphae (Thomas et al. 2002). In Southern analysis, the genomic DNA was digested with BamHI, EcoRV, NcoI, BglII, or $K p n I$ before being subjected to electrophoresis, and the blot was hybridized with the ${ }^{32} \mathrm{P}$-labeled cDNA of LIPI.

\section{Database searching and computational analysis.}

Deduced amino acid sequences of LIPI orthologues in other fungal species were obtained from the Broad Institute Whole Genome Database by running BlastP with a threshold value of $E \leq 1 \times 10^{-5}$. Multiple alignments were conducted using ClustalW. Signal peptides of lipases were predicted with SignalP 3.0. Other analyses of Lip1 were performed using appropriate software hosted by the ExPASy Proteomics Server.

\section{Expression of recombinant Lip1 in bacteria and yeast.}

Expression and purification of recombinant Lip1 from Escherichia coli was performed with the Qiaexpressionist kit (Qiagen, Valencia, CA, U.S.A.). The open-reading frame of $L I P 1$, excluding the predicted signal peptide and stop codon, was obtained from LIP1 cDNA by PCR and inserted into the pQE60 vector. The resulted construct, designated pQE60Lip1, was used to transform the E. coli M15 cells. Expression of recombinant Lip1 was induced with $1 \mathrm{mM}$ isopropyl $\beta$-D-1-thiogalactopyranoside. Preparation of cell lysate and purification of recombinant Lip1 under native conditions were performed according to the manufacturer's protocol.

For Lip1 expression in the nonlipolytic yeast $P$. pastoris, the LIPl open reading frame excluding the predicted signal peptide was amplified by PCR and inserted into the EasySelect Pichia expression vector pPICZ $\alpha \mathrm{A}$ (Invitrogen, Carlsbad, CA, U.S.A.) to generate plasmid pPICZ $\alpha$ A-Lip1. Plasmid DNA $(50 \mu \mathrm{g})$ of pPICZ $\alpha$ A-Lip1 or the empty vector pPICZ $\alpha$ A was linearized with PmeI and used to transform $P$. pastoris X-33 cells by the lithium chloride method described in the manufacturer's instructions. Transformants were cultured on or in plates or broth of buffered methanol-complex medium (BMMY; 1\% yeast extract, 2\% peptone, $100 \mathrm{mM}$ $\mathrm{KH}_{2} \mathrm{PO}_{4}$ [pH 6.0], $1.34 \%$ yeast nitrogen base, $4 \times 10^{-5}$ of biotin) containing $0.5 \%$ methanol as the recombinant protein inducer. 
Lipase activity assay.

Functional expression of the recombinant lipase was conducted by the emulsified tributyrin (Rapp and Backhaus 1992) and rhodamine B assays (Kouker and Jaeger 1987). For the tributyrin assay, $1 \%$ tributyrin ( $\mathrm{vol} / \mathrm{vol}$ ), and, for the rhodamine B assay, $2 \mu \mathrm{M}$ rhodamine B and $1 \%$ (vol/vol) appropriate substrate, were added into the medium.

\section{Preparation of the primary antibody.}

Rabbits were immunized with the purified recombinant Lip1 from E. coli. Immunoglobulin $\mathrm{G}$ (IgG) was purified from the antiserum using the Econo-Pac serum $\operatorname{IgG}$ purification kit (Bio-Rad, Richmond, CA, U.S.A.).

\section{Western analysis.}

Recombinant Lip1 purified from E. coli M15 cells or crude proteins extracted from $P$. pastoris X33 culture were separated by sodium dodecyl sulfate polyacrylamide gel electrophoresis with $12 \%$ resolving gel. The gel containing proteins from bacteria or yeast was either stained with Coomassie blue to visualize the protein bands or used for Western blotting, respectively. In the Western analysis, proteins were electroblotted onto a polyvinylidene difluoride membrane (Millipore, Billerica, MA, U.S.A.), blocked with $4 \%$ skim milk and $0.1 \%$ Tween 20 in Tris-buffered saline (TBS) $(25 \mathrm{mM}$ Tris- $\mathrm{HCl}, \mathrm{pH} 7.5$, and $200 \mathrm{mM} \mathrm{NaCl}$ ) for $2 \mathrm{~h}$, and then incubated with a 1:500 dilution of the primary antibody for $2 \mathrm{~h}$, followed by incubation with a 1:1,000 dilution of peroxidase-conjugated donkey antirabbit IgG (GE Healthcare, Piscataway, NJ, U.S.A.) for $1 \mathrm{~h}$. After washing, immunoreactive bands were detected by the enhanced chemiluminescence reagents using luminol and pcoumaric acid (Sigma-Aldrich, St. Louis).

\section{Immunofluorescence of Lip1 in fungal tissues.}

Immunofluorescence of Lip1 was performed modified after Kemen and associates (2005). Briefly, conidia or leaf sections from inoculated wheat were fixed in a mixture of acetic acid and ethanol (1:3, vol/vol) at room temperature for $2 \mathrm{~h}$ and then rehydrated successively in 100,70 , and $50 \%$ ethanol. The samples were blocked with $0.1 \%$ bovine serum albumin for $20 \mathrm{~min}$ followed by incubation with the primary antibody (1:100) at $4^{\circ} \mathrm{C}$ overnight. For the control treatment, samples were incubated with preimmune rabbit serum instead of the primary antibody. For fluorescence detection, samples were incubated with 1:1,000 FluoroLink Cy 3 IgG (GE Healthcare) for $30 \mathrm{~min}$ and, after washing with TBS (10 mM Tris-HCl, $150 \mathrm{mM}$ $\mathrm{NaCl}, \mathrm{pH}$ 7.6) (four times for 5 min each), mounted on slides with $80 \%$ glycerol and examined under a confocal laser-scanning electron microscope (LSM510; Carl Zeiss, Thornwood, NY, U.S.A.) with excitation and emission wavelengths of 543 and $570 \mathrm{~nm}$, respectively.

\section{Liquefaction of leaf epicuticular wax and pathogenicity assays.}

$P$. pastoris transformants harboring pPICZ $\alpha$ A-Lip1 or pPICZ $\alpha$ A were cultured in liquid BMMY media for $48 \mathrm{~h}$ and the supernatants were collected by centrifugation. The first leaves of 11-day-old wheat were dipped into the culture supernatants for 10,20 , or $30 \mathrm{~min}$. The effect of leaf treatment on the leaf surface wax was examined by SEM (SEM505; Philips, New York) immediately after the leaves were air dried. Plants were inoculated with $B$. graminis f. sp. tritici 12 h after Lip1 treatment. The conidial adhesion assay was performed following Rumbolz and associates (2000) at 6 hai. The early development of B. graminis f. sp. tritici was examined at 24 hai with SEM and powdery mildew symptoms were assessed at 120 hai.
The effect of Lip1 treatment on development of secondary hyphae was assayed on leaves 48 hai by dipping into the culture supernatant of $P$. pastoris transformants containing pPICZ $\alpha \mathrm{A}-$ Lip1 or pPICZ $\alpha$ A for $30 \mathrm{~min}$. The secondary hypha development was examined by SEM at 60 hai and the symptom development was assessed at 120 hai.

\section{Profiling of leaf epicuticular wax compositions.}

To investigate which wax components were liquefied by Lip1 treatment, 20 leaf fragments, $0.8 \mathrm{~cm}$ long, were treated for $30 \mathrm{~min}$ with $5 \mathrm{ml}$ of the culture supernatant of $P$. pastoris transformants containing pPICZ $\alpha$ A-Lip1 or pPICZ $\alpha$ A. Wax was extracted from untreated and treated leaves by dipping into chloroform/methanol $(1: 1, \mathrm{vol} / \mathrm{vol})$ for $15 \mathrm{~s}$. Wax components released to the culture supernatant after leaf treatment were extracted with the chloroform/methanol method described by Lalman and Bagley (2004). After drying under a stream of nitrogen, all wax extracts were derivatized using $50 \mu \mathrm{l}$ of pyridine containing N,O-bis (trimethylsilyl) fluoroacetamide and $1 \%$ (vol/vol) trimethylchlorosilane. GC and MS analyses were performed with a HP 6890 Series GC System (Global Medical Instrumentation, Ramsey, MN, U.S.A.) and a Trio 2000 gas chromatograph mass spectrometer (Agilent Technologies, Santa Clara, CA, U.S.A.), respectively, by following the protocol described by Millar and associates (1999). In the GC analysis, heptadecanoic acid (C17:0) and tricosanoic acid (C23:0) were used as the internal standards. Wax component quantification was based on the comparison of flame ionization detector peak areas between the component and heptadecanoic acid.

\section{Coating glass slides with wax components and B. graminis f. sp. tritici germination assay.}

Commercial long-chain fatty alcohols and alkanes, and wax extracted from untreated wheat leaves, were used to create a thin film on the surface of a cover slide $\left(2.2 \times 5.0 \mathrm{~cm}^{2}\right)$ following Reisige and associates (2006). The coated slides were inoculated with $B$. graminis f. sp. tritici conidia and conidial germination and differentiation were investigated at 24 hai. The experiments were conducted three times and, for each treatment, approximately 100 conidia were counted.

\section{ACKNOWLEDGMENTS}

We thank R. Hirji for technical support. This work was supported by the Natural Sciences and Engineering Research Council of Canada and the Canadian Wheat Board in the form of grants to Y. Wei and scholarships to J. Feng.

\section{LITERATURE CITED}

Berto, P., Belingheri, L., and Dehorter, B. 1997. Production and purification of a novel extracellular lipase from Alternaria brassicicola. Biotechnol. Lett. 19:533-536.

Berto, P., Comménil, P., Belingheri, L., and Dehorter, B. 1999. Occurrence of a lipase in spores of Alternaria brassicicola with a crucial role in the infection of cauliflower leaves. FEMS (Fed. Eur. Microbiol. Soc.) Microbiol. Lett. 180:183-189.

Bianchi, G., Lupotto, E., Borghi, B., and Corbellini, M. 1980. Cuticular wax of wheat. Planta 148:328-331.

Both, M., Eckert, S. E., Csukai, M., Müller, E., Dimopoulos, G., and Spanu, P. D. 2005. Transcript profiles of Blumeria graminis development during infection reveal a cluster of genes that are potential virulence determinants. Mol. Plant-Microbe Interact. 18:125-133.

Bourett, T. M., and Howard, R. J. 1990. In vitro development of penetration structures in the rice blast fungus Magnaporthe grisea. Can. J. Bot. 68:329-342.

Carver, T. L. W., and Gurr, S. J. 2006. Filamentous fungi on plant surfaces. Pages 368-397 in: Biology of the Plant Cuticle. M. Riederer and M. Müller, eds. Blackwell Publishing Ltd., Oxford.

Carver, T. L. W., Ingerson, S. M., and Thomas, B. J. 1996. Influences of host surface features on development of Erysiphe graminis and Erysi- 
phe pisi. Pages 255-256 in: Plant Cuticles: An Integrated Functional Approach. G. Kerstiens, ed. BIOS Scientific Publishers Ltd., Oxford.

Carver, T. L. W., Kunoh, H., Thomas, B. J., and Nicholson, R. L. 1999. Release and visualization of the extracellular matrix of conidia of Blumeria graminis. Mycol. Res. 103:547-560.

Chahinian, H., Nini, L., Boitard, E., Dubes, J. P., Comeau, L. C., and Sarda, L. 2002. Distinction between esterases and lipases: A kinetic study with vinyl esters and TAG. Lipids 37:653-662.

Chaubal, R., Wilmot, V. A., and Wynn, W. K. 1991. Visualization, adhesiveness and cytochemistry of the extracellular matrix produced by urediniospore germ tubes of Puccinia sorghi. Can. J. Bot. 69:20442054.

Clement, J. A., Porter, R., Butt, T. M., and Beckett, A. 1993. Germination and the role of extracellular matrix in adhesion of urediniospores of Uromyces viciae-fabae to synthetic surfaces. Mycol. Res. 97:585-593.

Clement, J. A., Martin, S. G., Porter, R., Butt, T. M., and Beckett, A. 1994 The role of hydrophobicity in attachment of urediniospores and sporelings of Uromyces. Germination and the role of extracellular matrix in adhesion of urediniospores of Uromyces viciae-fabae. Mycol. Res. 98:1217-1228.

Clement, J. A., Porter, R., Butt, T. M., and Beckett, A. 1997. Characteristics of adhesion pads formed during imbibition and germination of urediniospores of Uromyces viciae-fabae on host and synthetic surfaces. Mycol. Res. 101:1445-1458.

Comménil, P., Belingheri, L., and Dehorter, B. 1998. Antilipase antibodies prevent infection of tomato leaves by Botrytis cinerea. Physiol. Mol. Plant Pathol. 52:1-14.

Comménil, P., Belingheri, L., Bauw, G., and Dehorter, B. 1999. Molecular characterization of a lipase induced in Botrytis cinerea by components of grape berry cuticle. Physiol. Mol. Plant Pathol. 55:37-43.

Cooper, L. L. D., Oliver, J. E., De Vilbiss, E. D., and Doss, R. P. 2000 Lipid composition of the extracellular matrix of Botrytis cinerea germlings. Phytochemistry 53:293-298.

Dean, J. D., Goodwin, P. H., and Hsiang, T. 2002. Comparison of relative RT-PCR and northern blot analyses to measure expression of beta-1,3glucanase in Nicotiana benthamiana infected with Colletotrichum destructivum. Plant Mol. Biol. Rep. 20:347-356.

Deising, H., Nicholson, R. L., Haug, M., Howard, R. J., and Mengden, K. 1992. Adhesion pad formation and the involvement of cutinase and esterases in the attachment of uredospores to the host cuticle. Plant Cell 4:1101-1111.

Feng, J., Liu, G., Selvaraj, G., Hughes, G. R., and Wei, Y. 2005. A secreted lipase encoded by LIP1 is necessary for efficient use of saturated triglyceride lipids in Fusarium graminearum. Microbiology 151:39113921.

Francis, S. A., Dewey, F. M., and Gurr, S. J. 1996. The role of cutinase in germling development and infection by Erysiphe graminis f. sp. hordei. Physiol. Mol. Plant Pathol. 49:201-211.

Gandhi, N. N., Patil, N. S., Sawant, S. B., Joshi, J. B., Wangikar, P. P., and Mukesh, D. 2000. Lipase-catalyzed esterification. Catal. Rev. Sci. Eng. 42:439-480

Gilbert, R. D., Johnson, A. M., and Dean, R. A. 1996. Chemical signals responsible for appressorium formation in the rice blast fungus Magnaporthe grisea. Physiol. Mol. Plant Pathol. 48:335-346.

Gniwotta, F., Vogg, G., Gartmann, V., Carver, T. L. W., Riederer, M., and Jetter, R. 2005. What do microbes encounter at the plant surface? Chemical composition of pea leaf cuticular waxes. Plant Physiol. 139:519-530.

Green, J. R., Carver, T. L. W., and Gurr, S. J. 2002. The formation and function of infection and feeding structures. Pages 66-82 in: The Powdery Mildews-A Comprehensive Treatise. R. R. Bélanger, W. Bushnell, A. J. Dik, and T. L. W. Carver, eds. American Phytopathological Society Press, St. Paul, MN, U.S.A.

Hegde, Y., and Kolattukudy, P. E. 1997. Cuticular waxes relieve self-inhibition of germination and appressorium formation by the conidia of Magnaporthe grisea. Physiol. Mol. Plant Pathol. 51:75-84.

Jones, E. B. G. 1994. Fungal adhesion. Mycol. Res. 98:961-981.

Kemen, E., Kemen, A. C., Rafiqi, M., Hempel, U., Mendgen, K., Hahn, M., and Voegele, R. T. 2005. Identification of a protein from rust fungi transferred from haustoria into infected plant cells. Mol. Plant-Microbe Interact. 18:1130-1139.

Kinane, J., Dalvin, S., Bindslev, L., Hall, A., Gurr, S., and Oliver, R. P. 2000. Evidence that the cAMP pathway controls emergence of both primary and appressorial germ-tubes of barley powdery mildew. Mol. Plant-Microbe Interact. 13:494-502.

Klose, J., Moniz de Sá, M., and Kronstad, J. W. 2004. Lipid-induced filamentous growth in Ustilago maydis. Mol. Microbiol. 52:823-835.

Koch, K., Barthlott, W., Koch, S., Hommes, A., Wandelt, K., Mamdouh, H., De-Feyter, S., and Broekmann, P. 2006. Structural analysis of wheat wax Triticum aestivum, cv. 'Naturastar' L: From the molecular level to three dimensional crystals. Planta 223:258-270.

Kolattukudy, P. E. 1984. Cutinases from fungi and pollen. Pages 471-504 in: Lipases. B. Borgstrom and H. L. Brockman, eds. Elsevier, New York

Kolattukudy, P. E. 1985. Enzymatic penetration of the plant cuticle by fungal pathogens. Annu. Rev. Phytopathol. 23:223-250.

Kolattukudy, P. E. 2001. Polyesters in higher plants. Adv. Biochem. Eng. Biotechnol. 71:1-49.

Kouker, G., and Jaeger, K. E. 1987. Specific and sensitive plate assay for bacterial lipases. Appl. Environ. Microbiol. 53:211-213.

Kunoh, H., Yamaoka, N., Yoshioka, H., and Nicholson, R. L. 1988. Preparation of the infection court by Erysiphe graminis. I, Contact-mediated changes in morphology of the conidium surface. Exp. Mycol. 12:325335.

Lalman, J. A., and Bagley, D. M. 2004. Extracting long chain fatty acids from a fermentation medium. J. Am. Oil Chem. Soc. 81:105-110.

Li, D., Ashby, A. M., and Johnstone, K. 2003. Molecular evidence that the extracellular cutinase $\mathrm{Pbc} 1$ is required for pathogenicity of Pyrenopeziza brassicae on oilseed rape. Mol. Plant-Microbe Interact. 16:545552.

Liu, G., Sheng, X., Greenshields, D. L., Ogieglo, A., Kaminskyj, S., Selvaraj, G., and Wei, Y. 2005. Profiling of wheat class-III peroxidase genes derived from powdery mildew attacked epidermis reveals distinct sequence-associated expression patterns. Mol. Plant-Microbe Interact. 18:730-741.

Longhi, S., and Cambillau, C. 1999. Structure-activity of cutinase, a small lipolytic enzyme. Biochim. Biophys. Acta 1141:185-196.

Lotti, M., Grandori, R., Fusetti, F., Longhi, S., Brocca, S., Tramontano, A., and Alberghina, L. 1993. Cloning and analysis of Candida cylindracea lipase sequences. Gene 124:45-55.

Martinez, C., Nicolas, A., van Tilbeurgh, H., Egloff, M. P., Cudrey, C., Verger, R., and Cambillau, C. 1994. Cutinase, a lipolytic enzyme with a preformed oxyanion hole. Biochemistry 33:83-89.

Mendgen, K., and Hahn, M. 2002. Plant infection and the establishment of fungal biotrophy. Trends Plant Sci. 7:352-356.

Mercure, E. W., Leite, B., and Nicholson, R. L. 1994. Adhesion of ungerminated conidia of Colletotrichum graminicola to artificial hydrophobic surfaces. Physiol. Mol. Plant Pathol. 45:421-440.

Mercure, E. W., Kunoh, H., and Nicholson, R. L. 1995. Visualization of materials released from adhered ungerminated conidia of Colletotrichum graminicola. Physiol. Mol. Plant Pathol. 46:121-135.

Millar, A. A., Clemens, S., Zachgo, S., Giblin, E. M., Taylor, D. C., and Kunst, L. 1999. CUT1, an Arabidopsis gene required for cuticular wax biosynthesis and pollen fertility encodes a very-long-chain fatty acid condensing enzyme. Plant Cell 11:825-838.

Mims, C. W., Liljebjelke, K. A., and Richardson, E. A. 1995. Surface morphology wall structure and initial adhesion of conidia of the powdery mildew fungus Uncinuliella australiana. Phytopathology 85:352-358.

Nasser-Eddine, A., Hannemann, F., and Schäfer, W. 2001. Cloning and expression analysis of $\mathrm{Nhi}$, a gene encoding an extracellular lipase from the fungal pea pathogen Nectria haematococca MP VI Fusarium solani f. sp. pisi that is expressed in planta. Mol. Genet. Genomics 265:215224.

Nicholson, R. L., Yoshioka, H., Yamaoka, N., and Kunoh, H. 1988. Preparation of the infection court by Erysiphe graminis. II, Release of esterase enzyme from conidia in response to a contact stimulus. Exp. Mycol. 12:336-349.

Nielsen, K. A., Nicholson, R. L., Carver, T. L. W., Kunoh, H., and Oliver, R. P. 2000. First touch: An immediate response to surface recognition in conidia of Blumeria graminis. Physiol. Mol. Plant Pathol. 56:63-70.

Pascholati, S. F., Yoshioka, H., Kunoh, H., and Nicholson, R. L. 1992. Preparation of the infection court by Erysiphe graminis f. sp. hordeicutinase is a component of the conidial exudates. Physiol. Mol. Plant Pathol. 41:53-59.

Podila, G. K., Rogers, L. M., and Kolattukudy, P. E. 1993. Chemical signals from avocado surface wax triggers germination and appressorium formation in Colletotrichum gloeosporioides. Plant Physiol. 103:267272.

Rapp, P., and Backhaus, S. 1992. Formation of extracellular lipases by filamentous fungi yeasts and bacteria. Enzyme Microb. Technol. 14:938-943.

Reis, H., Pfiffi, S., and Hahn, M. 2005. Molecular and functional characterization of a secreted lipase from Botrytis cinerea. Mol. Plant Pathol. 6:257-267.

Reisige, K., Gorzelanny, C., Daniels, U., and Moerschbacher, B. M. 2006. The $\mathrm{C} 28$ aldehyde octacosanal is a morphogenetically active component involved in host plant recognition and infection structure differentiation in the wheat stem rust fungus. Physiol. Mol. Plant Pathol. 68:33-40.

Rumbolz, J., Kassemeyer, H. H., Steinmetz, V., Deising, H. B., Mendgen, K., Mathys, D., Wirtz, S., and Guggenheim, R. 2000. Differentiation of 
infection structures of the powdery mildew fungus Uncinula necator and adhesion to the host cuticle. Can. J. Bot. 78:409-421.

Sambrook, J., and Russell, D. W. 2001. Molecular Cloning: A Laboratory Manual. Cold Spring Harbor Laboratory Press, Cold Spring Harbor, NY, U.S.A.

Samuels, L., Kunst, L., and Jetter, R. 2008. Sealing plant surfaces: Cuticular wax formation by epidermal cells. Annu. Rev. Plant Biol. 59:683707.

Schmid, R. D., and Verger, R. 1998. Lipases: Interfacial enzymes with attractive applications. Angew. Chem. Int. Ed. Engl. 37:1608-1633.

Schrag, J. D., Li, Y., Wu, S., and Cygler, M. 1991. Ser-His-Glu triad forms the catalytic site of the lipase from Geotrichum candidum. Nature 351:761-764.

Senior, I. J., Hollomon, D. W., and Holloway, P. J. 1993. Unusual long chain monoenoic fatty acids in conidia of Erysiphe graminis. Phytochemistry 34:65-68

Shimada, Y., Sugihara, A., Iizumi, T., and Tominaga, Y. 1990. cDNA cloning and characterization of Geotrichum candidum lipase II. J. Biochem. 107:703-707.

Skamnioti, P., and Gurr, S. J. 2007. Magnaporthe grisea cutinase2 mediates appressorium differentiation and host penetration and is required for full virulence. Plant Cell 19:2674-2689.

Sugui, J. A., Leite, B., and Nicholson, R. L. 1998. Partial characterization of the extracellular matrix released onto hydrophobic surfaces by conidia and germlings of Colletotrichum graminicola. Physiol. Mol. Plant Pathol. 52:411-425.

Thomas, S. W., Glaring, M. A., Rasmussen, S. W., Kinane, J. T., and Oliver, R. P. 2002. Transcript profiling in the barley mildew pathogen Blumeria graminis by serial analysis of gene expression SAGE. Mol. Plant-Microbe Interact. 15:847-856.

Verger, R. 1997. 'Interfacial activation' of lipases: Facts and artifacts. Trends Biotechnol. 15:32-38.

Voigt, C. A., Schäfer, W., and Salomon, S. 2005. A secreted lipase of
Fusarium graminearum is a virulence factor required for infection of cereals. Plant J. 42:364-375.

Walton, J. D. 1994. Deconstructing the cell wall. Plant Physiol. 104:11131118.

Wei, Y., Zhang, Z., Andersen, C. H., Schmelzer, E., Gregersen, P. L., Collinge, D. B., Smedegaard-Petersen, V., and Thordal-Christensen, H. 1998. An epidermis/papilla-specific oxalate oxidase-like protein in the defence response of barley attacked by the powdery mildew fungus. Plant Mol. Biol. 36:101-112.

Wright, A. J., Thomas, B. J., and Carver, T. L. W. 2002a. Early adhesion of Blumeria graminis to plant and artificial surfaces demonstrated by centrifugation. Physiol. Mol. Plant Pathol. 61:217-226.

Wright, A. J., Thomas, B. J., Kunoh, H., Nicholson, R. L., and Carver, T. L. W. 2002b. Release and visualization of the extracellular matrix of conidia of Blumeria graminis. Physiol. Mol. Plant Pathol. 61:163-178.

Zabka, V., Stang, M., Bringmann, G., Vogg, G., Riederer, M., and Hildebrandt, U. 2008. Host surface properties affect prepenetration processes in the barley powdery mildew fungus. New Phytol. 177:251263.

Zhang, Z., Henderson, C., Perfect, E., Carver, T. L. W., Thomas, B. J., Skamnioti, P., and Gurr, S. J. 2005. Of genes and genomes, needles and haystacks: Blumeria graminis and functionality. Mol. Plant Pathol. 6:561-575.

\section{AUTHOR-RECOMMENDED INTERNET RESOURCES}

Broad Institute Whole Genome database: www.broad.mit.edu/annotation ClustalW: www.ebi.ac.uk/clustalw

ExPASy Proteomics Server, http://expasy.org

ExPASy PROSITE Carboxylesterases type-B signatures webpage: expasy.org/cgi-bin/nicedoc.pl?PDOC00112

SignalP 3.0 website: www.cbs.dtu.dk 